\title{
Salicylic Acid and Jasmonic Acid Signaling Defense Pathways Reduce Natural Bacterial Diversity on Arabidopsis thaliana
}

\author{
Joel M. Kniskern, M. Brian Traw, and Joy Bergelson \\ Department of Ecology and Evolution, University of Chicago, 1101 East 57th Street, Chicago 60637, U.S.A.
}

Submitted 16 April 2007. Accepted 10 August 2007.

\begin{abstract}
Terrestrial plants serve as large and diverse habitats for a wide range of pathogenic and nonpathogenic microbes, yet these communities are not well described and little is known about the effects of plant defense on microbial communities in nature. We designed a field experiment to determine how variation in two plant defense signaling pathways affects the size, diversity, and composition of the natural endophytic and epiphytic bacterial communities of Arabidopsis thaliana. To do this, we provide an initial characterization of these bacterial communities in one population in southwestern Michigan, United States, and we compare these two communities among $A$. thaliana mutants deficient in salicylic acid (SA) and jasmonic acid (JA) signaling defense pathways, controls, and plants with artificially elevated levels of defense. We identified 30 distinct bacterial groups on $A$. thaliana that differ in colony morphology and 16S rRNA sequence. We show that induction of SA-mediated defenses reduced endophytic bacterial community diversity, whereas plants deficient in JA-mediated defenses experienced greater epiphytic bacterial diversity. Furthermore, there was a positive relationship between total community size and diversity, indicating that relatively susceptible plants should, in general, harbor higher bacterial diversity. This experiment provides novel information about the ecology of bacteria on $A$. thaliana and demonstrates that variation in two specific plant-signaling defense pathways can influence bacterial diversity on plants.
\end{abstract}

Additional keywords: microbial diversity, phytobacteria, Pseudomonas, Xanthomonas.

Microbial communities of plants are diverse, consisting of harmful pathogens, benign epiphytes, and potentially beneficial symbionts (Beattie and Lindow 1995; Rosenblueth and Martínez-Romero 2006; Yang et al. 2001). Of the different kinds of microbes inhabiting plants, bacteria may be some of the most abundant, reaching densities as high as $10^{6}$ to $10^{7}$ cells $/ \mathrm{cm}^{2}$ (Hirano and Upper 2000; Lindow and Brandl 2003). Bacteria reside in the leaf interior (endophytes), which includes

J. M. Kniskern and M. B. Traw contributed equally to this work.

Corresponding author: J. Bergelson;

E-mail: jbergels@midway.uchicago.edu.

Present address of M. B. Traw: Department of Biological Sciences, University of Pittsburgh, 4249 Fifth Ave, Pittsburgh, PA 15260, U.S.A.

Nucleotide sequence data are available in the GenBank database under accession numbers EF154087 to 154189. intercellular spaces, substomatal cavities, and vascular tissues, as well as on the leaf surface (epiphytes) (Henis and Bashan 1986; Hirano and Upper 1983). Endophytic and epiphytic phytobacterial communities have been described on a number of plant hosts (Beattie and Lindow 1995; Horner-Devine et al. 2003; Krimm et al. 2005; Kuske et al. 2002; Marschner et al. 2001; Rosenblueth and Martínez-Romero 2006; Yang et al. 2001; Zinniel et al. 2002); these communities are known to vary across plant species (Dickinson et al. 1975; Ercolani 1978, 1991; Kinkel et al. 2000; Thompson et al. 1993; Yang et al. 2001) and can be highly dynamic, changing over the course of a growing season on a single plant (Ercolani 1991, Thompson et al. 1993). For example, Kinkel and associates (2000) showed that cucumber supports greater numbers of epiphytic bacteria and exhibits less within- and among-plant variation in total epiphytic abundance relative to several grasses. Furthermore, Ercolani (1991) found that the kinds of species composing the epiphytic community of olive leaves varied with leaf age and with sampling date over a 5-year time period. In addition to having a different species composition, older leaves harbored fewer species than younger leaves (Ercolani 1991), a pattern that also was observed on sugar beet by Thompson and associates (1993), who further demonstrated that bacterial epiphytic diversity was greatest during cool, wet months of the year. Variation in these bacterial community properties, including total bacterial abundance, diversity (i.e., the number and "evenness" of species), and species composition (i.e., the types of species) may have important consequences for the development of plant disease in nature and in agriculture; however, the full range of physical and biological mechanisms responsible for generating variation in phytobacterial communities are not well understood.

Plants have a variety of constitutive and induced defenses that may directly or indirectly influence community-level properties of phytobacteria. Some highly specialized defense mechanisms, such as gene-for-gene resistance (Flor 1971), target a relatively small number of pathogenic species. More general defense mechanisms, such as those activated by conserved microbial- or pathogen-associated molecular patterns (MAMPs or PAMPs) (Chisholm et al. 2006; Jones and Dangl 2006), have the potential to affect a much wider range of microbes. One would expect broad classes of plant defense to differentially impact the phytobacterial community. Specifically, variation in gene-for-gene interactions among plants probably generates variation in the abundance and distribution of a relatively small number of highly pathogenic species, whereas variation in more general forms of defense has the potential to influence a larger proportion of the phytobacterial community. There are presently little more than general expectations regarding the 
myriad effects of plant defense on community-level properties of phytobacteria, and there is a need to better understand exactly how different types of constitutive and induced plant defense influences the abundance, diversity, and species composition of microbial communities.

The putative effects of plant defense on phytobacterial community-level properties are likely to be strongest for endophytic communities, although plant defense also may alter the community dynamics of bacterial epiphytes. Several studies have shown that bacterial pathogens growing as epiphytes attain greater population size on susceptible relative to resistance plants (Daub and Hagedorn 1981; Henis and Bashan 1986; Hirano and Upper 1983; McGuire et al. 1991; Mew and Vera Cruz 1986). The extent to which we may generate specific predictions about the impacts of plant defense on endophytic and epiphytic bacterial communities is limited, however, in part because it is not clear if plant defense differentially affects pathogens and nonpathogens, but also because the relative abundance of pathogens and nonpathogens in these communities is not well described (Birgit and Sessitsch 2006; Zinniel et al. 2002).

To determine how variation in plant defense affects bacterial community-level properties, we are studying the interactions between Arabidopsis thaliana and bacteria that naturally colonize it in the wild. Although there is an extensive understanding of the molecular mechanisms of defense to bacterial pathogens in A. thaliana (Buell 2002; Glazebrook 2005; Katagiri et al. 2002), very little is known about the natural interactions between A. thaliana and bacterial pathogens (Goss et al. 2005; Jakob et al. 2002; Traw et al. in press; Tsuji and Somerville 1992). Bacterial surveys demonstrate that at least one population of A. thaliana in Michigan is infected by Xanthomonas campestris (Tsuji and Somerville 1992), while Pseudomonas syringae has been isolated from A. thaliana in several populations in Michigan and Indiana (Jakob et al. 2002) and $P$. viridiflava has been found in association with $A$. thaliana in populations throughout the United States and Europe (Goss et al. 2005; Jakob et al. 2002). These surveys do not describe how common or abundant these pathogens are on wild plants, nor do they reveal whether these species are dominant members of their ecological communities. This represents a gap in our understanding of the biology of A. thaliana-bacteria interactions.

A. thaliana has several defense responses to bacterial infection; two of these responses involve induced defense signaling pathways mediated by the plant hormones salicylic acid (SA) and jasmonic acid (JA). These induced defense signaling pathways suppress the growth of a wide range of microbial pathogens, including many different types of bacterial pathogens (Bostock 2005; Glazebrook 2005; Kunkel and Brooks 2002). For example, in A. thaliana, chemical elicitation of the SA signaling defense pathway suppresses the growth of $P$. syringae (Traw et al. 2003; Uknes et al. 1992) whereas genetic mutants deficient in SA signaling are more susceptible to $P$. syringae (Glazebrook et al. 1996; Jakob et al. 2007; Traw et al. 2003) and X. campestris (Rogers and Ausubel 1997; Ton et al. 2002). In addition, A. thaliana mutants deficient in JA signaling are more susceptible to Erwinia carotovora (Norman-Setterblad et al. 2000), P. viridiflava (Jakob et al. 2007), and X. campestris (Ton et al. 2002). The putatively broad and overlapping effects of both SA and JA signaling defense pathways on these bacterial pathogens suggests that many members of the natural phytobacterial community may be directly affected by variation in these two defense pathways, or indirectly affected through changes in competitive interactions within the community.

We designed a field experiment to test the hypothesis that variation in the SA and JA signaling defense pathways affects the abundance, diversity, and composition of the natural bacte- rial community of $A$. thaliana. To generate phenotypic variation in the SA and JA signaling defense pathways, we used genetic mutants that are deficient in either SA- or JA-mediated defenses (Bostock 2005; Glazebrook 2005; Kunkel and Brooks 2002). Specifically, we used sid2, which is deficient in the accumulation of SA (Dewdney et al. 2000); $n p r l$, which is deficient in SA signaling (Cao et al. 1994); and $\mathrm{fad} 3 / 7 / 8$, a triple mutant deficient in JA accumulation (McConn and Browse 1996). All of these mutants were created in the Columbia (Col) background which we used to represent wild-type levels of defense. We also sprayed Col plants with low concentrations of SA or JA sufficient to induce elevated expression of these pathways (Traw et al. 2003). The successful induction of experimental plants sprayed with these two chemical elicitors was verified independently by quantifying aliphatic glucosinolates which are known to increase in response to both SA and JA pathway induction (Kiddle et al. 1994; Kliebenstein et al. 2002; Mikkelsen et al. 2003). Application of SA or JA increased aliphatic glucosinolates by 91.3 and $97.5 \%$, respectively (Traw et al. in press). In addition, JA application reduced silique herbivory by $57.4 \%$ (Traw et al. in press), further suggesting that the chemical elicitors induced plant defenses.

We transplanted the mutants, the Col progenitor, and Col plants pre-induced for SA or JA signaling defense pathways into a natural population of $A$. thaliana in southwestern Michigan. This population of $A$. thaliana has been studied previously and is known to be large and diverse and to harbor bacterial pathogens (Goss et al. 2005; Jakob et al. 2002). Finally, we analyzed the abundance, diversity, and composition of a sample of the natural endophytic and epiphytic bacterial communities that colonized experimental $A$. thaliana at this site.

Community abundance was estimated as the total number of colony-forming units per leaf disk sample (CFU/disk). Diversity was assessed in two ways common to microbial studies. First, richness was defined as the total number of distinct bacterial groups present in a leaf sample and was included as an intuitive measure of diversity. Second, we also used the Shannon diversity index because it incorporates information on both richness and the relative "evenness" of different bacterial groups (Hughes and Bohannan 2004; Magurran 1988). For example, a leaf sample harboring $n$ bacterial groups in equal proportions would have a larger Shannon index value than a sample consisting of the same $n$ groups but dominated by only a subset of these groups. In this study, we quantified the similarity in bacterial community composition between leaf samples using a common community similarity index (Bray-Curtis) that uses data on the abundance of each bacterial group. Definitions of bacterial community composition similarity are quite distinct from diversity because the former rely on knowing the identity of bacterial groups and the extent to which the same groups are shared among different leaf samples, whereas the latter consider only the number and relative proportions of groups within a sample. Thus, estimates of diversity reveal how many different kinds of bacteria are found, on average, on each plant sample, while estimates of community composition similarity reveal whether the same kinds of bacteria are found across different samples.

\section{RESULTS}

\section{Bacterial identification.}

One of the goals of this study was to provide an initial characterization of a bacterial community of A. thaliana. We identified 36 different bacterial morphotypes from leaf samples on the basis of colony color, opacity, size, texture, edge shape, and symmetry. Two type strains and their replicates were not viable after storage and are identified hereafter by their origi- 
nal strain identifications: MEJ080 and MEJ090. The remaining morphotypes were sequenced for a fragment of the 16S rRNA region and compared with published sequences using BLAST. Most strains exhibited strong homology (>98\%) to a single species. In general, there was a one-to-one correspondence between each unique morphotype and a unique species or genus of bacteria. However, in four cases, sequences from two or more similar morphotypes exhibited high homology to a single species or genus and subsequently were collapsed into a single bacterial group. This occurred for morphotypes assigned to Bacillus cereus, Curtobacterium flaccumfaciens, Pseudoclavibacter helvolus, and Sphingomonas spp. These morphotypes may represent distinct species whose identity cannot be resolved with our $16 \mathrm{~S}$ sequences or, alternatively, may represent phenotypic variation within a single species. Within-group sequence variation of the remaining bacterial groups indicates that colony morphotype was a conservative predictor of genetically defined groups (Table 1). Specifically, estimates of average pairwise nucleotide diversity $(\mathrm{Pi})$ range from 0 to 0.0552 . Smaller values of Pi support a one-to-one correspondence between colony morphotype and species, whereas larger values of Pi may reflect the presence of more than one species of similar morphotype. Finally, bacterial group accumulation curves suggest that we observed most of the bacterial group diversity that potentially could be detected within the limits of our sampling approach. However, it is likely that additional sampling, particularly of epiphytes, would have yielded novel bacterial groups (Fig. 1).

The abundance and distribution of bacteria on A. thaliana.

Our samples of the endophytic and epiphytic bacterial communities of $A$. thaliana consisted of a small number of highly abundant groups and a large number of relatively rare groups
(Table 1; Fig. 2). In all, 24 different bacterial groups were identified from endophytic community samples, 12 of which were present on at least $10 \%$ of these plants. Endophytic community samples were dominated in abundance by four groups that exhibited high $16 \mathrm{~S}$ sequence similarity to known pathogens: X. campestris, Pseudomonas viridiflava, $P$. syringae, and Agrobacterium tumefaciens. Together, these bacterial groups accounted for $79.6 \%$ of all endophytic bacterial colonies identified in this work.

The epiphytic community consisted of 27 different bacterial groups, 11 of which were present on least $10 \%$ of plants. Morphotypes identified as X. campestris, Nocardia corynebacterioides, Flavobacterium spp., and $A$. tumefaciens dominated the epiphytic community, and together these four groups accounted for $56.1 \%$ of all epiphytic colonies.

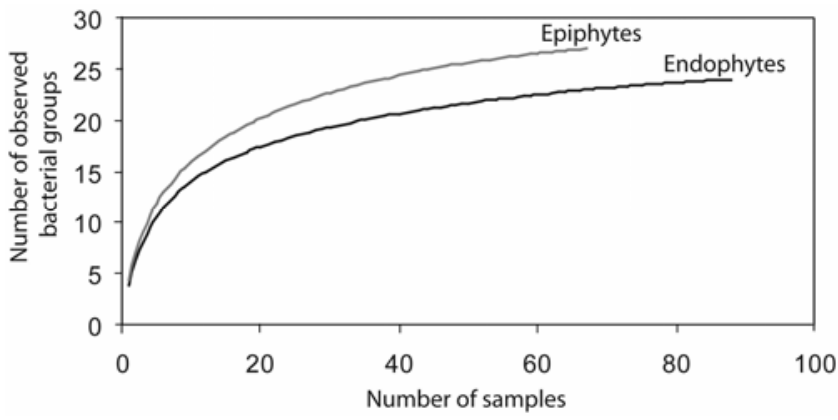

Fig. 1. Bacterial group accumulation curves for endophytic and epiphytic community samples. Accumulation curves are presented solely to illustrate the efficacy of sampling in capturing bacterial diversity; statistical differences between endophytic and epiphytic community diversity are compared elsewhere.

Table 1. Summary statistics for bacterial groups ${ }^{\mathrm{a}}$

\begin{tabular}{|c|c|c|c|c|c|c|c|c|}
\hline Bacterial group & $n$ & Length & $\mathbf{S}$ & $\mathbf{P i}$ & $P($ end $)(\%)$ & P (epi) (\%) & $A$ (end) & A (epi) \\
\hline Agrobacterium tumefaciens & 5 & 1,385 & 32 & 0.011 & 38.9 & 33.7 & 1.46 & 1.47 \\
\hline Agromyces salentinus & 1 & $\ldots$ & $\ldots$ & $\ldots$ & 0 & 2.6 & 0 & 0.08 \\
\hline Arthrobacter sp. & 3 & 1,427 & 34 & 0.0522 & 5.6 & 27.3 & 0.16 & 0.99 \\
\hline Bacillus cereus & 7 & 1,361 & 15 & 0.0036 & 37.8 & 3.9 & 1.05 & 0.13 \\
\hline B. megaterium & 3 & 1,405 & 23 & 0.0108 & 17.8 & 3.9 & 0.52 & 0.17 \\
\hline B. mycoides & 4 & 1,384 & 39 & 0.0156 & 16.7 & 0 & 0.4 & 0 \\
\hline Clavibacter michiganensis & 2 & 1,423 & 0 & 0 & 0 & 2.6 & 0 & 0.11 \\
\hline Curtobacterium fangii & 1 & $\ldots$ & $\ldots$ & $\ldots$ & 1.1 & 0 & 0.06 & 0 \\
\hline C. flaccumfaciens & 9 & 1,340 & 17 & 0.0032 & 8.9 & 22.1 & 0.27 & 0.8 \\
\hline C. herbarum & 1 & $\ldots$ & $\ldots$ & $\ldots$ & 0 & 1.3 & 0 & 0.06 \\
\hline Erwinia persicinus & 2 & 1,425 & 6 & 0.0067 & 1.1 & 0 & 0.05 & 0 \\
\hline Flavobacterium sp. & 6 & 1,429 & 47 & 0.013 & 25.6 & 52 & 1.03 & 1.74 \\
\hline Frigoribacterium sp. & 2 & 1,422 & 15 & 0.0107 & 11.1 & 10.4 & 0.42 & 0.41 \\
\hline Kineococcus-like sp. & 2 & 1,413 & 25 & 0.0183 & 1.1 & 2.6 & 0.03 & 0.07 \\
\hline Nocardia corynebacterioides & 5 & 1,453 & 77 & 0.0225 & 18.9 & 41.6 & 0.63 & 1.66 \\
\hline Paenibacillus pabuli & 2 & 1,446 & 15 & 0.0107 & 0 & 5.2 & 0 & 0.2 \\
\hline Pantoea ananatis & 2 & 1,350 & 25 & 0.0198 & 2.2 & 1.3 & 0.11 & 0.05 \\
\hline Pseudoclavibacter helvolus & 3 & 1,415 & 13 & 0.0066 & 10 & 1.3 & 0.29 & 0.04 \\
\hline Pseudomonas fluorescens & 3 & 1,424 & 10 & 0.0045 & 3.3 & 2.6 & 0.08 & 0.21 \\
\hline P. flavescens & 3 & 1,422 & 1 & 0.0005 & 2.2 & 5.2 & 0.15 & 0.1 \\
\hline P. poae & 5 & 1,434 & 22 & 0.0061 & 2.2 & 11.7 & 0.1 & 0.46 \\
\hline P. syringae & 4 & 1,428 & 16 & 0.0072 & 32.2 & 9.1 & 1.26 & 0.39 \\
\hline P. viridiflava & 9 & 1,449 & 39 & 0.0059 & 58.9 & 24.7 & 2.22 & 1 \\
\hline Rhodococcus erythropolis & 2 & 1,419 & 4 & 0.0044 & 2.2 & 6.5 & 0.09 & 0.26 \\
\hline Sphingomonas sp. & 6 & 1,423 & 162 & 0.0552 & 12.2 & 15.6 & 0.47 & 0.62 \\
\hline Streptomyces chartreuses & 1 & $\ldots$ & $\ldots$ & $\ldots$ & 2.2 & 2.6 & 0.06 & 0.07 \\
\hline Subtercola pratensis & 2 & 1,424 & 6 & 0.007 & 0 & 1.3 & 0 & 0.03 \\
\hline Xanthomonas campestris & 4 & 1,321 & 45 & 0.0185 & 61.1 & 58.4 & 2.56 & 2.45 \\
\hline MEJ080 & 0 & $\ldots$ & $\ldots$ & $\ldots$ & 0 & 19.5 & 0 & 0.83 \\
\hline MEJ090 & 0 & $\ldots$ & $\ldots$ & $\ldots$ & 6.7 & 9.1 & 0.31 & 0.37 \\
\hline
\end{tabular}

${ }^{a}$ Putative names were assigned based on $97 \%$ or greater sequence similarity to GenBank sequences; $n$ is the number of sequences per bacterial group, Length is the length of the aligned sequence, $\mathrm{S}$ is the number of segregating sites, $\mathrm{Pi}$ is the average pairwise nucleotide distance, $\mathrm{P}$ refers to the percentage of samples harboring a bacterial group, A refers to average group abundance $\left(\log _{10} \mathrm{CFU} / \mathrm{disk}\right)$, end refers to samples from the endophytic community, and epi refers to the epiphytic community. 
Samples of the epiphytic and endophytic communities differed in abundance $\left(\log _{10} \mathrm{CFU} /\right.$ disk), diversity (Shannon diversity index), and community composition (Bray-Curtis similarity index). Paired $t$ tests show that epiphytic samples were significantly lower in total abundance than endophytic samples $(t=$ $3.38, P=0.0013)$ and were significantly more diverse according to the Shannon index $(t=2.11, P=0.0392)$ but not according to richness $(t=0.39, P=0.6966)$. This suggests that, although endophytic and epiphytic communities had a similar number of bacterial groups, the relative frequencies of groups were more even within the epiphytic community. In addition, nonparametric Wilcoxon/Kruskal-Wallis tests showed that community similarity between endophytic and epiphytic samples was significantly smaller relative to comparisons made within endophytic samples $\left(X^{2}=4.68, P=0.0305\right)$ and epiphytic samples $\left(X^{2}=\right.$ 12.96, $P=0.0003$ ) (Fig. 3). In other words, different sets of bacterial groups tended to dominate endophytic and epiphytic samples. These results confirm the expectation that the endophytic and epiphytic bacterial communities of Arabidopsis thaliana are distinct.

\section{Effects of plant phenotype on community abundance, diversity, and composition.}

A second goal of this study was to determine how the bacterial community of $A$. thaliana might be influenced by variation in plant defense. Analysis of variance (ANOVA) was used to determine how the plant defense phenotypes may have altered the abundance $\left(\log _{10} \mathrm{CFU} /\right.$ disk) of the endophytic and epiphytic bacterial communities. There was no significant main effect of plant phenotype on either endophytic $\left(\mathrm{F}_{5,72}=0.63, P\right.$ $=0.6765)$ or epiphytic $\left(\mathrm{F}_{5,51.6}=1.64, P=0.1653\right)$ community abundance. Furthermore, preplanned contrast tests that compare plant phenotypes with altered defense to the Col wild type show no significant differences (Fig. 4). To determine the effects of plant phenotype on diversity, ANOVAs of richness and of the Shannon diversity index were performed. There was no significant main effect of plant phenotype on either endophytic richness $\left(\mathrm{F}_{5,72.1}=1.33, P=0.262\right)$ or the Shannon diversity index $\left(\mathrm{F}_{5,72.1}=1.8, P=0.1236\right)$. However, preplanned contrast tests that compare plant phenotypes with altered defense to the Col wild type reveal that the induction of the SA defense pathway significantly reduced endophytic diversity as measured through

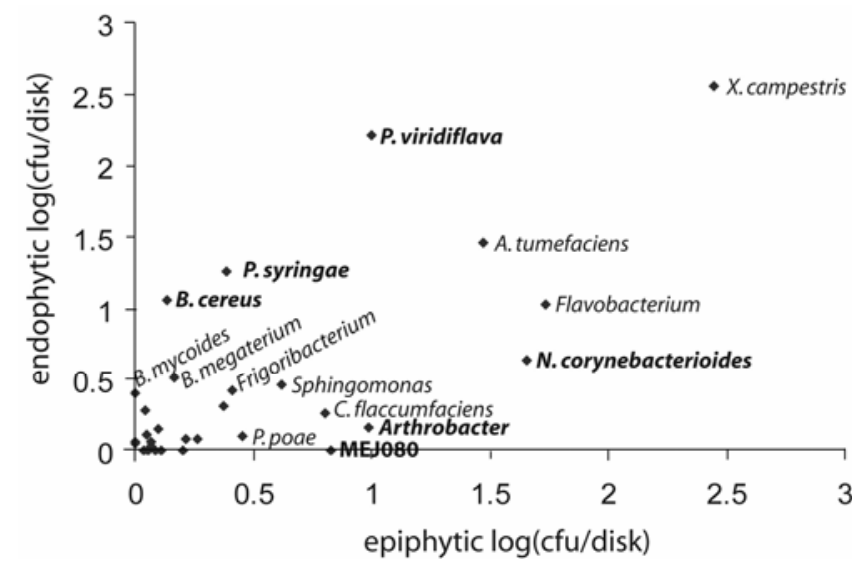

Fig. 2. Average abundance ( $\log _{10} \mathrm{CFU} /$ disk) of each of the 30 bacterial groups within the endophytic and epiphytic communities. Putative names are provided for the more abundant groups. In bold are bacterial groups that exhibited significantly more colonies in either the endophytic or epiphytic communities. This habitat bias was measured as the percentage of colonies derived from paired endophytic and epiphytic samples for each bacterial group; significance was evaluated with Wilcoxon's signed-ranks tests followed by a sequential Bonferroni test with an $\alpha$ value of 0.05 . both richness $\left(\mathrm{F}_{1,72.1}=4.08, P=0.0472\right)$ and the Shannon diversity index $\left(\mathrm{F}_{1,72.1}=4.91, P=0.0298\right)$ (Fig. 4).

We next wanted to determine whether the reduction in bacterial diversity on SA-treated plants derived from a community-wide response. To do this, we used Wilcoxon's signedranks test, which ranks the absolute difference in bacterial group population size $\left(\log _{10} \mathrm{CFU} /\right.$ disk) on $\mathrm{Col}$ plants and $\mathrm{Col}$ plants treated with SA, and then determines if the magnitude of negative and positive responses are equivalent though a comparison of these ranks (Sokal and Rolf 2001). This analysis demonstrates that the negative effects of SA defense pathway induction significantly exceeded the positive effects $(P=$ 0.0304). Indeed, 12 of 18 bacterial groups showed a tendency for reduced population sizes in Col plants treated with SA relative to $\mathrm{Col}$ controls (Fig. 5A).

In contrast to plants with elevated SA-mediated defenses, no other plant phenotypes, including sid2-1 and nprl deficient in SA-mediated defenses, exhibited a significant difference in diversity relative to the Col wild type (Fig. 4). Furthermore, no community-wide response was observed on these two SA-mediated defense mutants according to Wilcoxon's signed-ranks test (nprl: $P=0.7285$; sid2: $P=0.4304$ ) (Fig. 5B and C). Thus, whereas the induction of SA-mediated defenses reduced bacterial endophytic diversity, the inhibition of SA-mediated defenses through mutation to SID2 or NPR1 did not enhance endophytic diversity.

The effects of plant defense on epiphytic diversity were quite different. There was a significant overall effect of plant phenotype on richness for epiphytic community samples $\left(\mathrm{F}_{5,51.2}=\right.$ 3.42, $P=0.0097$ ) and a similar but nonsignificant result was obtained for the Shannon diversity index $\left(\mathrm{F}_{5,51.2}=2.39, P=\right.$ 0.1044). In this case, contrast tests that compare plants with altered defense to the Col plants reveal that the $f a d 3 / 7 / 8$ mutant harbored significantly greater diversity than Col plants as measured through both richness $\left(\mathrm{F}_{1,51.3}=12.52, P=0.0009\right)$ and the Shannon diversity index $\left(\mathrm{F}_{1,51.3}=4.9, P=0.0313\right)$ (Fig. 4). However, no other plant phenotypes differed significantly in epiphytic diversity relative to the Col wild type (Fig. 4). Again, we were interested in determining whether the increase in diversity on the fad $3 / 7 / 8$ mutant was due to a community-wide response. This increase in diversity also appears to derive from a shared response by members of the epiphytic community, because the positive effects of $f a d 3 / 7 / 8$ on epiphytic population sizes significantly exceeded negative effects (Wilcoxon's signed-ranks test: $P=0.0124$ ), and 16 of the 22 bacterial groups exhibited a tendency for elevated population sizes on $\mathrm{fad} 3 / 7 / 8$ relative to $\mathrm{Col}$ plants (Fig. 5D). These results indicate that endophytic and epi-

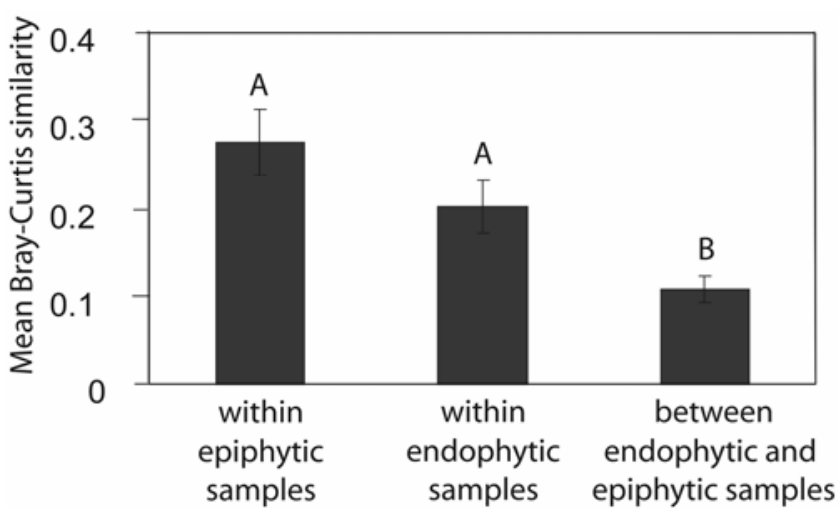

Fig. 3. Epiphytic community samples differ in bacterial group composition relative to endophytic community samples. Different letters indicate significant differences assessed with nonparametric Wilcoxon/Kruskal-Wallis tests $(P<0.05)$. Bars represent one standard error of the mean. 
phytic community diversity responds differently to variation in SA and JA signaling defense pathways.

In contrast, we found no evidence that endophytic or epiphytic community composition was affected by variation in SA or JA signaling defense pathways. First, Bray-Curtis community similarity comparisons between samples from the same plant phenotypes (e.g., Col versus Col and nprl versus $n p r l$ ) were indistinguishable (results not shown; $P>0.05$ for all relevant comparisons); in other words, community composition within the different plant phenotypes was of similar consistency. Second, Bray-Curtis community similarity comparisons between samples that shared the same plant phenotype (e.g., Col versus Col and nprl versus nprl) were not significantly different from comparisons between samples that derived from different plant phenotypes (e.g., Col versus $n p r l$ ) (results not shown; $P>0.05$ for all relevant comparisons); thus, homogeneity in community composition among plant phenotypes was similar in scale to homogeneity within plant phenotypes. Together, these results indicate that plant phenotype had no detectable effect on bacterial community composition.

\section{Association between community abundance and diversity.}

Regressions were performed to determine how bacterial community abundance was related to bacterial community diversity in A. thaliana. There was a significantly positive relationship between total bacterial community size and diversity for both epiphytic and endophytic communities (Fig. 6). To determine whether this relationship was general to all plant phe- notypes, analysis of covariance (ANCOVA) was performed on diversity estimates where transformed estimates of total community abundance ( $\log _{10} \mathrm{CFU} /$ disk) were included as a covariate. ANCOVAs of epiphytic community richness and the Shannon diversity index show significant interactions involving plant phenotype $\left(\mathrm{F}_{5,39.9}=2.63, P=0.0378\right.$ and $\mathrm{F}_{5,41.3}=2.65, P=$ 0.0362 , respectively) that are absent in ANCOVAs of endophytic community diversity. Additional analyses of epiphytic community abundance and diversity indicate that the interaction involving plant phenotype is due to variation in the strength (but not direction) of this positive relationship (not shown).

\section{DISCUSSION}

The molecular ecology of plant-microbe interactions is an active field, but the potential effects of plant defense on microbial communities have received little attention (Horner-Devine et al. 2003). A number of studies from different plants document patterns of bacterial community composition, relative species abundance, and differences among plant species in bacterial communities (Beattie and Lindow 1995; Ercolani 1991; Kinkel et al. 2000; Krimm et al. 2005; Kuske et al. 2002; Marschner et al. 2001; Rosenblueth and MartinezRomero 2006; Thompson et al. 1993; Yang et al. 2001; Zinniel et al. 2002). These studies indicate that the endophytic and epiphytic bacterial communities of plants are diverse, consisting of pathogens, saprophytes, and beneficial bacteria. Yet, despite an extensive understanding of the molecular biology of plantbacteria interactions, little is known about how traits related to

\section{Endophytic Community}

Epiphytic Community
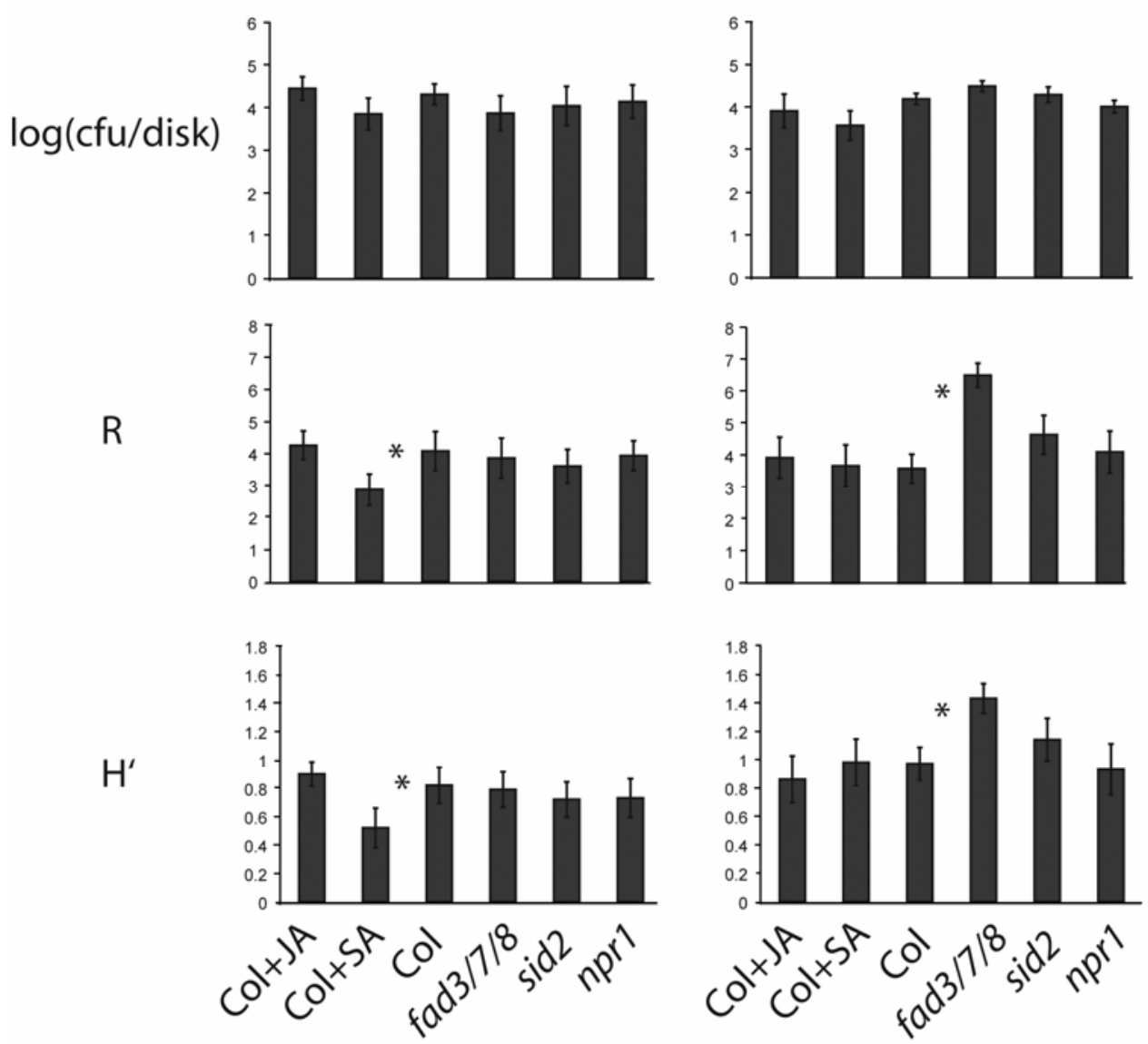

Fig. 4. Interior and exterior bacterial communities respond differently to variation in plant phenotype. Data are derived from all plants. An asterisk (*) indicates significance at $P<0.05$ from preplanned contrast tests, $\mathrm{R}=$ richness (number of groups), and $\mathrm{H}^{\prime}=\mathrm{Shannon}$ diversity index. Bars represent one standard error of the mean. 
plant defense, physiology, or secondary chemistry influence patterns of bacterial diversity and community composition. Nowhere is the potential to address this issue so great, and the gap in our understanding of ecology and molecular biology so wide, as in the model plant $A$. thaliana. The molecular mechanisms of microbial defense have been investigated in $A$. thaliana for over 20 years (Kunkel 1996; Meyerowitz and Somerville 1994), whereas almost nothing is known about the composition of its natural bacterial communities. The major goals of this work were to provide an initial description of part of the natural bacterial community of $A$. thaliana and to conduct an experiment that is, to the best of our knowledge, the first to examine how variation in plant defense affects patterns of diversity within a natural microbial community.

\section{The natural bacterial communities of $A$. thaliana.}

Our initial survey of a culturable sample of the bacterial diversity from $A$. thaliana identified 36 distinct bacterial mor- photypes that were assigned to 30 different bacterial groups on the basis of colony morphotype and $16 \mathrm{~S}$ sequence. Three of the bacterial groups that dominated samples of the endophytic bacterial community showed $97 \%$ or greater sequence similarity to $X$. campestris, $P$. viridiflava, and $P$. syringae. These three species are known to induce both disease symptoms and the expression of defense genes in laboratory infections of $A$. thaliana (Buell 2002; Jakob et al. 2007; Katagiri et al. 2002), and all three of these pathogens have been isolated from $A$. thaliana within approximately 75 miles of this experimental site (X. campestris: Michigan [Tsuji and Somerville 1992]; $P$. viridiflava: Indiana and Michigan [Goss et al. 2005; Jakob et al. 2002] P. syringae: Indiana [Jakob et al. 2002]). The majority of colonies identified as these three pathogens derived from the endophytic community samples, which is consistent with their putative role as pathogens of $A$. thaliana (Table 1; Fig. 2). Consequently, this work indicates that these three pathogens, along with Agrobacterium tumefaciens, a pathogen with wide
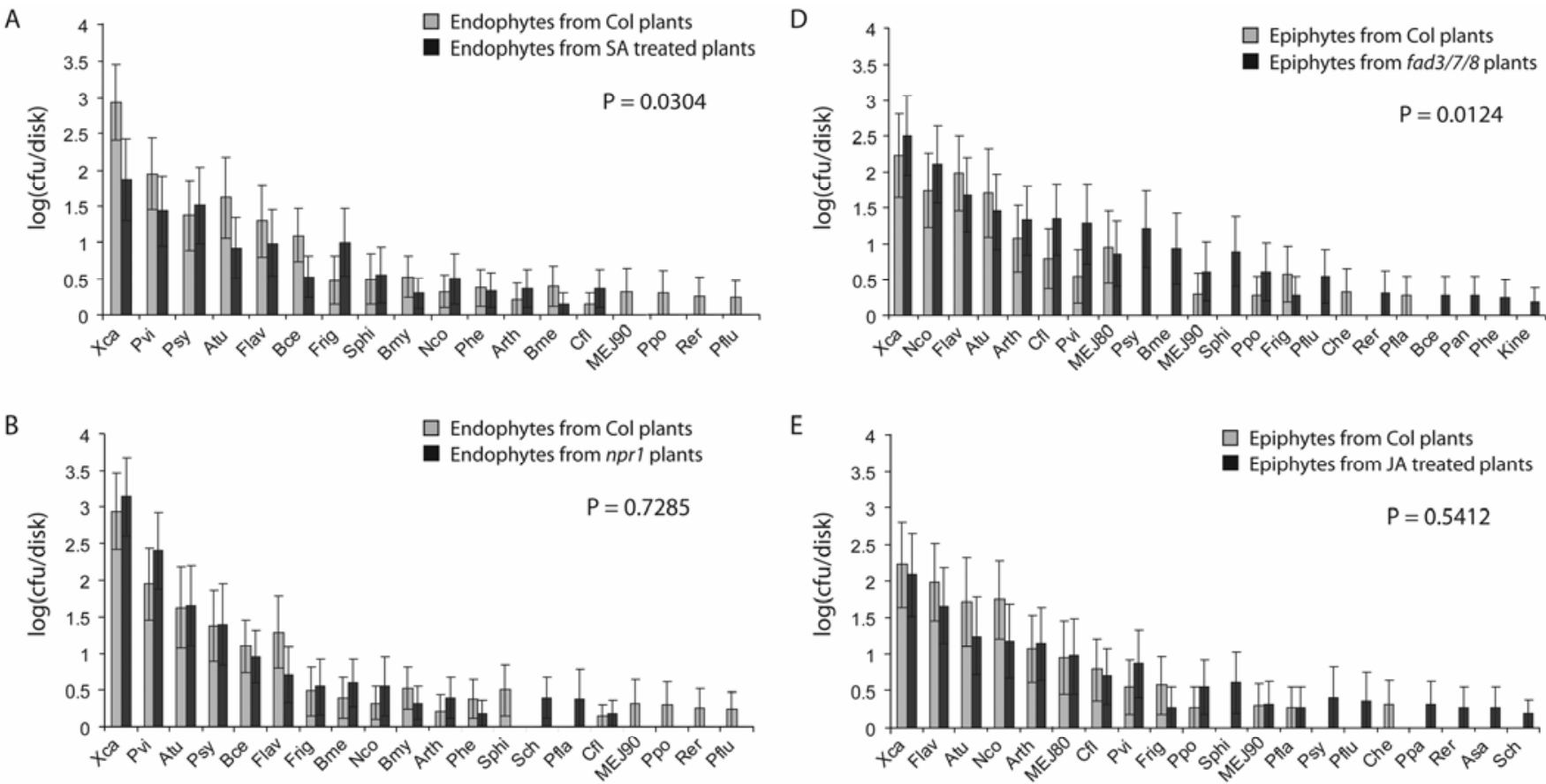

$\mathrm{E}$
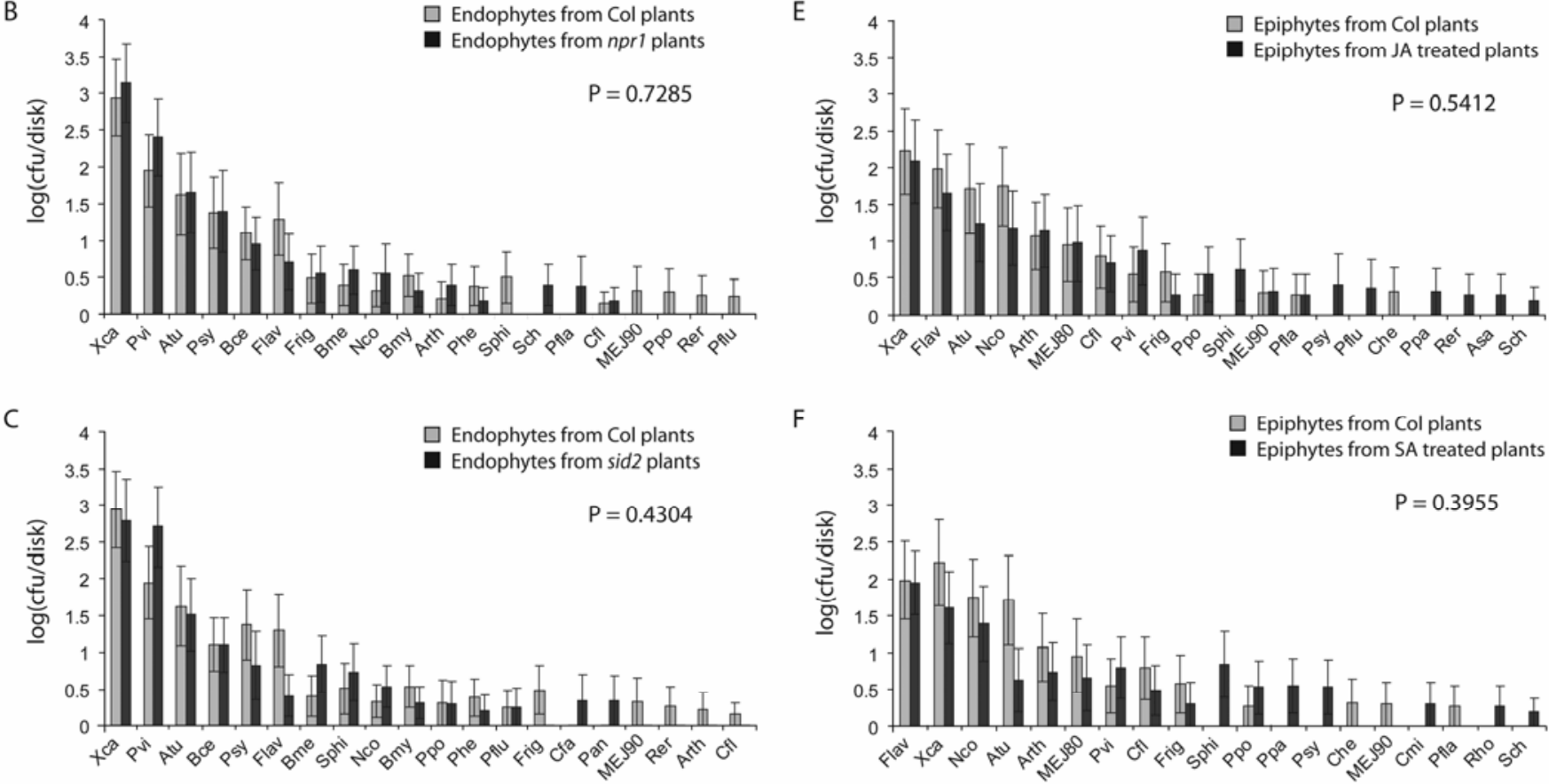

Fig. 5. Average population size ( $\log _{10} \mathrm{CFU} /$ disk) of individual members of $\mathbf{A}$, the endophytic community in wild-type Columbia (Col) (light bars) and Col + salicylic acid (SA) (dark bars); B, the endophytic community in wild-type Col (light bars) and $n p r l$ (dark bars); C, the endophytic community in wild-type Col (light bars) and sid2 (dark bars); D, the epiphytic community in wild-type Col (light bars) and fad3/7/8 plants (dark bars); E, the epiphytic community in wild-type Col (light bars) and $\mathrm{Col}+$ jasmonic acid (JA) (dark bars); and F, the epiphytic community in wild-type Col (light bars) and Col + SA (dark bars). Groups are ordered by combined population size from left (highest) to right (lowest). Bars represent one standard error of the mean. A significant response of community to variation in plant defense was assessed with a nonparametric Wilcoxon's signed-ranks test based on the population size of bacterial groups. Bacterial group abbreviations: Atu $=$ Agrobacterium tumefaciens, Asa $=$ Agromyces salentinus, Arth $=$ Arthrobacter, $\mathrm{Bce}=$ Bacillus cereus, $\mathrm{Bme}=$ B. megaterium, $\mathrm{Bmy}=$ B. mycoides, Cmi $=$ Clavibacter michiganensis, $\mathrm{Cfa}=$ Curtobacterium fangii, $\mathrm{Cfl}=$ C. flaccumfaciens, $\mathrm{Che}=$ C. herbarum, Epe $=$ Erwinia persicinus, Flav $=$ Flavobacterium $\mathrm{sp} .$, Frig $=$ Frigoribacterium sp., Kine $=$ Kineococcus-like sp., Nco $=$ Nocardia corynebacterioides, $\mathrm{Ppa}=$ Paenibacillus pabuli, Pan $=$ Pantoea ananatis, $\mathrm{Phe}=$ Pseudoclavibacter helvolus, $\mathrm{Pflu}=$ Pseudomonas fluorescens, $\mathrm{Pfla}=$ P. flavescens, $\mathrm{Ppo}=P$. poae, $\mathrm{Psy}=P$. syringae, $\mathrm{Pvi}=P$. viridiflava, $\mathrm{Rer}=$ Rhodococcus erythropolis, $\mathrm{Sphi}=$ Sphingomonas $\mathrm{sp} ., \mathrm{Sch}=$ Streptomyces chartreuses, $\mathrm{Spr}=$ Subtercola pratensis, and $\mathrm{Xca}=$ Xanthomonas campestris . 
host range (Escobar and Dandekar 2003), may be dominant members of the endophytic community of Arabidopsis thaliana. Interestingly, a relatively common (approximately $20 \%$ ) morphotype identified as B. cereus also showed a statistical bias in abundance within endophytic relative to epiphytic samples (Fig. 2). This species is not known to be pathogenic on A. thaliana, and some strains of B. cereus are even known to promote plant growth (Bloemberg and Lugtenberg 2001). The presence of putative nonpathogens in our samples is consistent with previous work indicating that nonpathogens may be common members of endophytic bacterial communities (Rosenblueth and Martínez -Romero 2006; Shishido et al. 1995; Zinniel et al. 2002).

Samples of the epiphytic bacterial community were significantly more diverse than those of the endophytic community as measured through both richness, defined as the number of different bacterial groups, and the Shannon diversity index, a diversity measure that incorporates information on both richness and the relative evenness of different groups (Hughes and Bohannan 2004; Magurran 1988). Some of the more common inhabitants of the epiphytic community were identified as $N$. corynebacteroides, Curtobacterium spp., and Flavobacterium spp., groups that have been isolated as epiphytic saprophytes of crops (Beattie and Lindow 1995; Ercolani 1991; Thompson et al. 1993). Two other common bacterial groups from epiphytic samples were identified as X. campestris and Agrobacterium tumefaciens (Table 1). The high prevalence and abundance of these two groups in both epiphytic and endophytic samples is consistent with previous work demonstrating that plant pathogens often attain large epiphytic population sizes alongside epiphytic saprophytes on the leaf surface (Beattie and Lindow 1995; Ercolani 1991; Hirano and Upper 1983, 2000).

Although approximately two-thirds of bacterial groups were isolated from both endophytic and epiphytic samples, samples from these two communities nonetheless were different in composition. More specifically, quantification of the similarity in the abundance of the different bacterial groups between pairs of samples revealed that the endophytic and epiphytic communities consisted of a significantly different suite of dominant bacteria. The actual differences in abundance, diversity, and composition between these communities are likely to be even larger than reported here, because there likely was some contamination between epiphytic and endophytic samples of the same leaf. Such contamination is practically unavoidable in phytobacterial surveys (Hirano and Upper 1986; Kinkel 1997), but previous work suggests that only 0.4 to $2 \%$ of nonpathogenic epiphytes survive surface sterilization, presumably due to shelter in protected sites (Beattie and Lindow 1995), and we found similar rates of sterilization survival for two randomly picked strains recovered from this experiment (MEJ074: $P$. fluorescens, 0\% survival; MEJ110: Flavobacterium sp., 5\% survival). More importantly, any contamination that did occur should be unbiased with respect to plant phenotype.

\section{Effects of plant defense on bacterial communities.}

This experiment demonstrates that variation in the SA and JA signaling defense pathways alters both the abundance and diversity of the endophytic and epiphytic bacterial communities of $A$. thaliana. There was a positive relationship between total community abundance and diversity estimated by richness and the Shannon diversity index (Fig. 6). The strength and direction of this relationship suggests that relatively susceptible plant phenotypes should, in general, harbor higher bacterial diversity. Although this is not necessarily surprising, the nature of this relationship could not be predicted a priori because it seemed equally likely that highly aggressive pathogens could dominate susceptible plants, leading to a negative relationship between community abundance and diversity.

Suppressive effects of the SA signaling defense pathway were experienced by endophytic bacterial communities. Plants

\section{Endophytic Community}
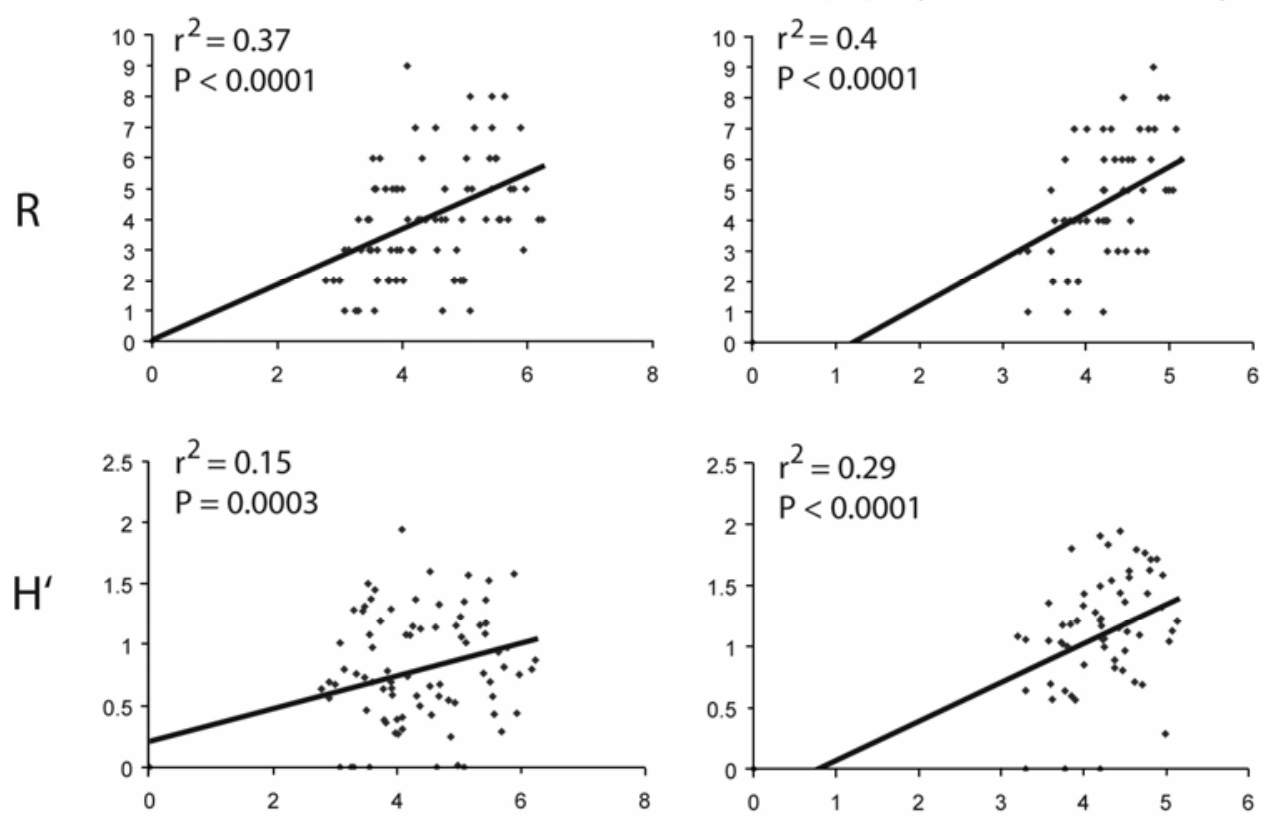

\section{$\log (\mathrm{cfu} / \mathrm{disk})$}

Fig. 6. Interior and exterior leaf samples exhibit a significant positive relationship between diversity and total community size. $\mathrm{R}=$ richness (number of groups) and $\mathrm{H}^{\prime}=$ Shannon diversity index. Total community size is represented as $\log _{10} \mathrm{CFU}$ per sampled leaf disk. 
with elevated SA-mediated defenses had lower endophytic diversity and supported an average of one fewer bacterial groups relative to Col plants (Fig. 4). Furthermore, the effects of the SA signaling defense pathway were broad and members of the endophytic community as a whole experienced reduced population sizes on SA-treated plants (Fig. 5A). Although endophytic community abundance tended to be lower in plants with elevated SA-mediated defenses, this difference was not significant for the subset of plants sampled for diversity. However, in a separate analysis conducted on all plants in this experiment (including those where bacteria were not identified for community diversity and composition analyses), plants with elevated SA-mediated defenses exhibited a significant reduction in endophytic community abundance (Traw et al. in press). Furthermore, plants treated with SA had significantly elevated biomass and fitness relative to Col wild-type plants, indicating that these changes to the endophytic bacterial community impacted the performance of plant hosts (Traw et al. in press).

Despite the suppressive effects of elevated SA-mediated defenses, we found no corresponding increase in community abundance or diversity on plants deficient in SA signaling; specifically, plants lacking functional versions of NPR1 or SID2, two genes necessary for wild-type levels of SA-mediated defenses (Cao et al. 1994; Dewdney et al. 2000). One explanation for these observations is that bacterial colonization and growth was limited by the natural field environment, resulting in smaller differences in total bacterial abundance between SA mutants and the Col wild type than have been observed in laboratory studies involving single pathogens, where conditions are amenable to high bacterial growth and SA mutants can support bacterial population sizes that are several orders of magnitude greater than those observed here (Glazebrook et al. 1996; Jakob et al. 2007; Rogers and Ausubel 1997; Ton et al. 2002; Traw et al. 2003). Interestingly, Heidel and associates (2004) found that the nprl mutant had a smaller rosette diameter relative to the Col wild type at a North Carolina field site but not in a growth chamber experiment. Although the cause of this difference in plant size is unknown, Heidel and associates (2004) hypothesized that elevated growth of natural soil microbes on $n p r l$ plants could be responsible. Although we also observed that $n p r l$ plants were significantly smaller with respect to biomass than Col plants in our experiment (Col: $130.08 \pm$ $19.91 \mathrm{~g} ;$ nprl: $95.66 \pm 15.66 \mathrm{~g} ; P=0.0028$ ), our bacterial data do not support the hypothesis that $n p r l$ plants experienced elevated bacterial infection. Furthermore, sid2 plants in our experiment did not differ in biomass relative to Col plants (sid2: $134.3 \pm 17.46 \mathrm{~g} ; P=0.6872$ ). Thus, although it is still possible that a more exhaustive survey of the bacterial, oomycete, fungal, and viral microbiota of entire A. thaliana plants might reveal one or more pathogens that overcolonizes $n p r l$ (but not sid2), an alternative explanation for these results is that the performance of $n p r l$ is influenced in the field by an unidentified physical (i.e., abiotic) stress.

In contrast to the endophytic community, elevated SA-mediated defenses had no significant effects on epiphytic diversity, and members of the epiphytic community did not exhibit a shared response to elevated SA-mediated defenses (Fig. 5F). This may derive from a preponderance of bacterial groups that are relatively insensitive to the effects of SA-mediated defenses within the epiphytic community, although this hypothesis awaits experimental verification. On the other hand, epiphytic diversity was significantly impacted by variation in the JA signaling pathway. In particular, epiphytic diversity showed a marked increase on $\mathrm{fad} 3 / 7 / 8$ plants lacking functional versions of three fatty acid desaturase genes (FAD3, FAD7, and FAD8) necessary for the production of wild-type levels of JA; fad $3 / 7 / 8$ plants had an average of three additional bacterial groups relative to $\mathrm{Col}$ plants (Fig. 4). Furthermore, the combined effects of FAD3, FAD7, and FAD 8 were general to the epiphytic community, because 18 of the 22 groups found on fad3/7/8 exhibited a lower abundance on Col plants (Fig. 5D). Interestingly, the largest epiphytic community size occurred on fad3/7/8 plants and both community size and diversity tended to be reduced on Col plants with elevated JA-mediated defenses. However, these individual differences were not large enough to be statistically significant and further work is needed to determine how variation in the JA signaling defense pathway may affect bacterial epiphytes and their community dynamics, particularly because the fad3/7/8 mutant also might influence bacterial diversity through another plant trait such as lipid production (McConn and Browse 1996).

Finally, both endophytic and epiphytic community compositions were unaffected by changes in plant defense. This is not necessarily surprising because each community sample tended to harbor, an average, 2 to 6 bacterial groups, and a small number of the 30 bacterial groups identified in this survey dominated these samples (Fig. 2). Thus, whereas SA-mediated defenses reduced richness by an average of one bacterial group per plant, and $f a d 3 / 7 / 8$ plants harbored an additional three groups per plant, these changes appear to be random with respect to bacterial group identity.

Although the primary goals of this study were to describe the resident bacterial community of A. thaliana and to characterize its response to changes in plant defense, we had also hoped to describe the response of individual bacterial groups to variation in plant defense. However, the colonization of plants by bacterial groups was uneven, making it difficult to estimate the effects of plant defense on individual groups due to the inherent noise in the data. Indeed, nonparametric analyses show that none of these bacterial groups was significantly affected by variation in these plant defense pathways. Nonetheless, it is intriguing that a well-studied species like $P$. syringae, which is known to be suppressed by SA-mediated defenses in the lab (Glazebrook et al. 1996; Jakob et al. 2007; Traw et al. 2003; Uknes et al. 1992), showed no sign of reduced endophytic growth on plants with elevated SA-mediated defenses in the field, whereas $P$. viridiflava, a pathogen that does not respond to variation in SA-mediated defenses in the lab (Jakob et al. 2007), showed a trend toward reduced growth in SA-treated plants (Fig. 5A). These patterns suggest that single-strain inoculation in a laboratory environment may not necessarily predict the growth of a pathogen within a complex natural community. Specifically, understanding interactions among bacteria of both a direct (e.g., competition for resources) and indirect (e.g., induction of plant defenses) nature may be important for predicting the growth of pathogens within complex microbial communities of wild plants.

\section{Conclusions.}

This experiment demonstrates that variation in two signaling defense pathways of $A$. thaliana altered the abundance and diversity of bacteria colonizing these plants. These results confirm the intuitive expectation that bacterial endophytes will respond rapidly to changes in systemic plant defense, but these results also show that the epiphytic community on the leaf surface may be affected by variation in defense induction within the plant. Consequently, natural variation in the induction of systemic defenses among plants within a population or between populations may generate spatial and temporal variation in the community dynamics of microbes that depend upon plants for survival. Moreover, it follows that evolutionary change in systemic defenses could have long-lasting effects on microbial community dynamics by changing the abundance and diversity of microbes that can be supported by a plant population. Given that bacteria 
have the potential to rapidly induce systemic plant defense (Bostock 2005; Glazebrook 2005; Kunkel and Brooks 2002) and may act as agents of natural selection on plant defense (Traw et al. in press), one exciting area for further study is understanding the potential ecological and evolutionary feedback loops involving plant defense and microbial community dynamics.

\section{MATERIALS AND METHODS}

\section{Experimental design.}

Seed of the Col-0 ecotype (referred to here as Col for brevity), sid2 (also known as eds16) (Dewdney et al. 2001), nprl (Cao et al. 1994), and fad3/7/8 (McConn and Browse 1996) were planted into plug trays containing a 1:1 mixture of Premier Pro-Mix and Metromix in the University of Chicago greenhouse. These trays were placed into a cold room without light for 3 days and then transferred to a growth chamber with 12 -h days at $20^{\circ} \mathrm{C}$. Col seedlings were assigned randomly to receive either $1 \mathrm{mM} \mathrm{SA} \mathrm{(Sigma} \mathrm{\# S7401)} \mathrm{to} \mathrm{induce} \mathrm{the} \mathrm{SA} \mathrm{sig-}$ naling defense pathway, $1 \mathrm{mM}$ JA (Sigma \#J-2500) to induce the JA signaling defense pathway (Traw et al. 2003), or a water spray. Both SA and JA solutions were neutralized to a $\mathrm{pH}$ of 7. Plants were treated with $0.6 \mathrm{ml}$ of these chemical elicitors 3 days prior to transplantation and with approximately $2 \mathrm{ml}$ once midway through the experiment. Seedlings of the sid2, nprl, and $f a d 3 / 7 / 8$ mutants all received a water spray during elicitor applications.

Each seedling initially was assigned randomly to either a control or aphid addition treatment where aphids were added to plants by hand. The aphid addition treatment was not successful in generating biologically relevant differences in aphid numbers between treated and control plants and will not be discussed further. However, we include this treatment factor in statistical analyses when appropriate. Seedlings were transplanted on 15 April 2004 within the border of a natural population of A. thaliana at the Michigan State University Southwest Michigan Research and Extension Center. A split-plot design was used, where two replicates of each treatment group were assigned to random positions within each block and one replicate of each plant phenotype ( $\mathrm{Col}, \mathrm{Col}+\mathrm{SA}, \mathrm{Col}+\mathrm{JA}$, sid2, nprl, or fad $3 / 7 / 8$ ) was assigned a random spatial position within a treatment group.

\section{Bacterial enumeration and identification.}

Near the end of this experiment, plants from four blocks were harvested and returned to the laboratory; each plant was sealed within a plastic bag and transported in a chilled cooler. A single disk of fixed size $\left(0.28 \mathrm{~cm}^{2}\right)$ was removed from an area in the middle of one leaf per plant with a paper hole punch. Senescing leaves were not sampled but otherwise leaves were chosen at random. Leaf disks were surface sterilized in $70 \%$ ethanol and then ground in sterile buffer $(10 \mathrm{mM}$ $\mathrm{MgSO}_{4}$ ) (Jakob et al. 2002). For three of these four blocks, the leaf disk first was vortexed in sterile buffer for 10 to $20 \mathrm{~s}$ prior to surface sterilization to liberate bacterial epiphytes from the leaf surface. Solutions from both endophytic and epiphytic samples were serially diluted and plated on King's B (KB) media. Two to four negative controls lacking a leaf disk were processed in the same manner to confirm the absence of contamination. Bacteria were allowed to grow for 4 days, after which time bacterial colonies were counted to estimate the total bacterial community size for each sample (CFU/disk). Bacterial colonies then were classified on the basis of six variables: color, opacity, growth rate, texture, edge shape, and symmetry (Hirano and Upper 1983; Zinniel et al. 2002). Samples from one block were scored independently by two individuals to confirm lack of observer bias.
To verify that morphotype identification represented genetically defined groups for community diversity and composition analyses, one to nine strains from each morphotype were sequenced for a fragment of the 16S rRNA region (Birgit and Sessitsch 2006; Zinniel et al. 2002). Strains were stored at $80^{\circ} \mathrm{C}$ in a $15 \%$ glycerol solution and grown in liquid $\mathrm{KB}$ overnight at $28^{\circ} \mathrm{C}$, and DNA was extracted using the Puregene DNA purification system (Gentra Systems, Minneapolis, MN, U.S.A.). For each strain, a fragment of the $16 \mathrm{~S}$ region then was polymerase chain reaction-amplified and sequenced (forward primer: AGAGTTTGATCCTGGCTCAG, reverse primer: AAGGAGGTGATCCAGCC), which yielded sequences up to $1.4 \mathrm{~kb}$ in length. Cycle sequencing of amplified fragments was conducted using Big Dye version 3.1 and visualized on an ABI3730XL automated sequencer (Applied Biosystems, Foster City, CA, U.S.A.). Sequences were assembled and manually edited using Sequencher version 4.1.4 (Gene Codes, Ann Arbor, MI, U.S.A.) and representative sequences from each morphotype have been deposited into GenBank (numbers EF154087 to 154189). Sequences were compared for homology to named bacteria using the BLAST program. A colony morphotype was assigned a putative species name when all strains from that morphotype exhibited $97 \%$ or greater similarity to a single species. Otherwise, a morphotype was given only a putative genus designation. In no case did strains from a single morphotype exhibit high similarity to different genera. Sequences were aligned using ClustalW and compared for the number of segregating sites and the average pair-wise difference using the TASSEL program.

\section{Statistical analyses.}

Once bacterial morphotypes had been placed into groups and given putative identifications, statistical differences among endophytic and epiphytic samples were assessed. Habitat bias in presence and abundance was quantified for all three blocks where paired endophytic and epiphytic samples were collected from the same leaf. The significance of this bias for these paired samples was evaluated for each bacterial group using the nonparametric Wilcoxon's signed-ranks test (Sokal and Rohlf 2001) followed by a sequential Bonferroni correction (Rice 1989).

The total number of CFU per leaf disk was used as an estimate of total bacterial community abundance. Bacterial diversity was assessed in two ways common to microbial diversity studies: richness was defined as the number of distinct bacterial groups present in a sample and the Shannon diversity index was used to provide information on group evenness within samples (Hughes and Bohannan 2004; Magurran 1988). Values of CFU/disk were $\log _{10}$ transformed to satisfy assumptions of normality for ANOVA, whereas richness and Shannon's diversity index required no transformation. Paired $t$ tests were used to evaluate differences in community abundance and diversity between paired endophytic and epiphytic samples from the same leaf. ANOVA of the split-plot design was implemented with the PROC MIXED procedure of SAS (Carey, NC, U.S.A.) to assess the effects of plant phenotype on community abundance and diversity. Plant phenotype and treatment were considered fixed effects in these analyses whereas block was considered a random effect (Littell et al. 1996). The Satterwaithe procedure was invoked to estimate the appropriate degrees of freedom in all analyses. Preplanned contrasts were used to determine whether plant phenotypes altered bacterial community abundance or diversity by comparing the five different plant phenotypes with altered defense $(\mathrm{Col}+\mathrm{SA}, \mathrm{Col}+$ JA, $n p r 1$, sid2, and fad3/7/8) to Col plants. Finally, regressions and ANCOVAs were performed to determine how total community abundance may influence diversity. 
To quantify differences in community composition, we calculated three common similarity indices (Bray-Curtis, MorisitaHorn, and Chao-Jaccard) based on the abundance of each of the 30 bacterial groups between all pairs of plants using R. K. Cowell's EstimateS software (University of Connecticut, Storrs, CT, U.S.A.). We used a small subset of these comparisons in our analyses made at a common spatial scale; pairs of plants were chosen for community composition comparisons from different subplots within blocks. To test the hypothesis that samples of the epiphytic and endophytic communities were of different composition, we calculated community similarity values for interior versus interior, exterior versus exterior, and interior versus exterior pairs of samples and then determined whether interior and exterior values were significantly different from the former two types of comparison; all pairs of samples shared the same plant phenotype and treatment. Likewise, to determine whether variation in SA or JA defense signaling pathways altered community composition, we calculated similarity indices for pairs of plants within each phenotype (e.g., Col versus Col and nprl versus nprl) and compared these with pairs involving a plant with altered defense and the Col wild type (e.g., Col versus nprl); all comparisons were made with pairs from the same treatment and bacterial community (endophytic or epiphytic). Because the distributions of similarity index values were highly non-normal following transformation, these data were analyzed with nonparametric Wilcoxon/Kruskal-Wallis tests within JMP 5.1.2 (SAS Institute 2004). All three similarity indices were highly correlated; for simplicity, only the Bray-Curtis similarity values are presented.

\section{ACKNOWLEDGMENTS}

This research was supported by grants from the National Institute of Health and National Science Foundation to J. Bergelson and by a Dropkin Foundation Postdoctoral Fellowship to M. B. Traw. We thank S. Lindow and two anonymous reviewers for comments on the manuscript; and J. Price, A. Wendlandt, and V. Yovovich of the University of Chicago and D. Francis of the Southwest Michigan Research and Extension Center for providing valuable assistance in the field.

\section{LITERATURE CITED}

Beattie, G. A., and Lindow, S. E. 1995. The secret life of foliar bacterial pathogens on leaves. Annu. Rev. Phytpathol 33:145-172.

Birgit, R., and Sessitsch, A. 2006. Bacterial endophytes of the wildflower Crocus albiflorus analyzed by characterization of isolates and by a cultivation-independent approach. Can. J. Microbiol. 52:140-149.

Bloemberg, G. V., and Lugtenberg, B. J. J. 2001. Molecular basis of pant growth promotion and biocontrol by rhizobacteria. Curr. Opin. Plant Biol. 4:343-350.

Bostock, R. M. 2005. Signal crosstalk and induced resistance: straddling the line between cost and benefit. Annu. Rev. Phytpathol 43:545-580.

Buell, C. R. 2002. Interactions between Xanthomonas species and Arabidopsis thaliana. In: The Arabidopsis Book. The American Society of Plant Biologists, Rockville, MD, U.S.A.

Cao, H., Bowling, S. A., Gordon, S., and Dong, X. 1994. Characterization of an Arabidopsis mutant that is nonresponsive to inducers of systemic acquired resistance. Plant Cell 6:1583-1592.

Chisholm, S. T., Coaker, G., Day, B., and Staskawicz, B. J. 2006. Hostmicrobe interactions: shaping the evolution of the plant immune response. Cell 124:803-814

Daub, M. E., and Hagedorn, D. J. 1979. Resistance of Phaseolus line WBR to Pseudomonas syringae. Phytopathology 69:946-951.

Dewdney, J., Reuber, T. L., Wildermuth, M. C., Devoto, A., Stutius, L. M. Drummond, E. P., and Ausubel, F. M. 2000. Three unique mutants of Arabidopsis identify eds loci required for limiting growth of a biotrophic fungal pathogen. Plant J. 24:205-218.

Dickinson, C. H, Austin, B., and Goodfellow, M. 1975. Quantitative and qualitative studies of the phylloplane bacteria from Lolium perenne. J. Gen. Appl. Microbiol. 91:157-166.

Ercolani, G. L. 1978. Pseudomonas savastanoi and other bacteria coloniz- ing the surface of olive leaves in the field. J. Gen. Appl. Microbiol. 109:245-257.

Ercolani, G. L. 1991. Distribution of epiphytic bacteria on olive leaves and the influence of leaf age and sampling time. Microb. Ecol. 21:35-48.

Escobar, M. A., and Dandekar, A. M. 2003. Agrobacterium tumefaciens as an agent of disease. Trends Plant Sci. 8:380-386.

Flor, H. H. 1971. Current status of the gene-for-gene concept. Annu. Rev. Phytopathol. 9:275-296.

Glazebrook, J. 2005. Contrasting mechanisms of defense against biotrophic and necrotrophic pathogens. Annu. Rev. Phytopathol. 43:205-227.

Glazebrook J., Rogers, E. E., and Ausubel, F. M. 1996. Isolation of Arabidopsis mutants with enhanced disease susceptibility by direct screening. Genetics 143:973-982.

Goss, E. M., Kreitman, M., and Bergelson, J. 2005. Genetic diversity, recombination and cryptic clades in Pseudomonas viridiflava infecting natural populations of Arabidopsis thaliana. Genetics 169:21-35.

Heidel, A. J., Clarke, J. D., Antonovics, J., and Dong, X. 2005. Fitness costs of mutations affecting the systemic acquired resistance pathway in Arabidopsis thaliana. Gtenetics 168:2197-2206.

Henis, Y., and Bashan, Y. 1986. Epiphytic survival of bacterial leaf pathogens. In: Microbiology of the Phyllosphere. N. J. Fokkema and J. van den Heuvel, eds. Cambridge University Press, New York.

Hirano, S. S., and Upper, C. D. 1983. Ecology and epidemiology of foliar bacterial plant pathogens. Annu. Rev. Phytopathol. 21:243-270.

Hirano, S. S., and Upper, C. D. 2000. Bacteria in the leaf ecosystem with emphasis on Pseudomonas syringae - a pathogen, ice nucleus, and epiphyte. Microbiol. Mol. Biol. Rev. 64:624-653.

Horner-Devine, M. C., Carney, K. M., and Bohannan, B. J. M. 2003. An ecological perspective on bacterial biodiversity. Proc. R. Soc. Lond. B. Biol. Sci. 271:113-122.

Hughes, J. B., and Bohannan, B. J. M. 2004. Application of ecological diversity statistics in microbial ecology. In: Molecular Microbial Ecology Manual. Kluwer Academic, Boston.

Jakob, K., Goss, E. M., Araki, H., Van, T., Kreitman, M., and Bergelson, J. 2002. Pseudomonas viridiflava and $P$. syringae-natural pathogens of Arabidopsis thaliana. Mol. Plant-Microbe Interact. 15:1195-1203.

Jakob, K., Kniskern, J. M., and Bergelson, J. 2007. The role of pectate lyase and jasmonic acid defense response in Pseudomonas viridiflava virulence. Mol. Plant-Microbe Interact. 20:146-158.

Jones, J. D. G., and Dangl, J. L. 2006. The plant immune system. Nature 444:323-329

Katagiri, F., Thilmony, R., and He, S. Y. 2002. The Arabidopsis-Pseudomonas syringae interaction. In: The Arabidopsis Book. The American Society of Plant Biologists, Rockville, MD, U.S.A.

Kiddle, G. A., Doughty, K. J., and Wallsgrove, R. M. 1994. Salicylic acidinduced accumulation of glucosinolates in oilseed rape (Brassica napus L.) leaves. J. Exp. Bot. 45:1343-1346.

Kinkel, L. L. 1997. Microbial population dynamics on leaves. Annu. Rev. Phytopathol. 35:327-347.

Kinkel, L. L., Wilson, M., and Lindow, S. E. 2000. Plant species and plant incubation conditions influence variability in epiphytic bacterial population size. Microb. Ecol. 39:1-11.

Kliebenstein, D. J., Figuth, A., and Mitchell-Olds, T. 2002. Genetic architecture of plastic methyl jasmonate responses in Arabidopsis thaliana. Genetics 161:1685-1696.

Krimm, U. Abanda-Nkpwatt, D., Schwab, W., and Schreiber, L. 2005. Epiphytic microorganisms on strawberry plants (Fragaria ananassa cv. Elsanta): identification of bacterial isolates and analysis of their interaction with leaf surfaces. FEMS (Fed. Eur. Microbiol. Soc.) Microbiol. Ecol. 53:483-492.

Kunkel, B. N. 1996. A useful weed put to work: genetic analysis of disease resistance in Arabidopsis thaliana. Trends Genet. 12:63-69.

Kunkel, B. N., and Brooks, D. M. 2002. Cross talk between signaling pathways in pathogen defense. Curr. Opin. Plant Biol. 5:325-331.

Kuske, C. R., Ticknor, L. O., Miller, M. E., Dunbar, J. M., Davis, J. A., Barns, S. M., and Belnap, J. 2002. Comparison of soil bacterial communities in rhizospheres of three plant species and the interspaces in an arid grassland. Appl. Environ. Microbiol. 68:1854-1863.

Lindow, W. E., and Brandl, M. T. 2003. Microbiology of the phyllosphere. Appl. Environ. Microbiol. 69:1875-1883.

Littell, R. C., Miliken, G. A., Stroup, W. W., and Wolfinger, R. D. 1996. SAS System for Mixed Models. SAS Institute Inc., Cary, NC, U.S.A.

Magurran, A. E. 1988. Ecological Diversity and Its Measurement. Princeton University Press, Princeton, NJ, U.S.A.

Marschner, P., Yang, C. H., Lieberei, R., and Crowley, D. E. 2001. Soil and plant specific effects on the bacterial community composition in the rhizosphere. Soil Biol. Biochem. 33:1437-1445.

McConn, M., and Browse, J. 1996. The critical requirement for linolenic acid is pollen development, not photosynthesis, in an Arabidopsis mutant. Plant Cell 8:403-416. 
McGuire, R. G., Jones, J. B., and Scott, J. W. 1991. Epiphytic populations of Xanthomonas campestris pv. vesicatoria on tomato cultigens resistant and susceptible to bacterial spot. Plant Dis. 75:606-609.

Mew, T. W., and Vera Cruz, C. M. 1986 Epiphytic colonization of host and non-host plants by phytopathogenic bacteria. In: Microbiology of the Phyllosphere. N. J. Fokkema and J. van den Heuvel, eds. Cambridge University Press, New York.

Meyerowitz, E. M., and Somerville, C. R. 1994. Arabidopsis. Cold Spring Harbor Laboratory Press, Plainview, NY, U.S.A.

Mikkelsen, M. D., Petersen, B. L., Glawischnig, E., Jensen, A. B., Andreasson, E., and Halkier, B. A. 2003. Modulation of CYP79 genes and glucosinolate profiles in Arabidopsis by defense signaling pathways. Plant Physiol. 131:298-308.

Norman-Setterblad, C., Vidal, S., and Palva, E. T. 2000. Interacting signal pathways control defense gene expression in Arabidopsis in response to cell wall-degrading enzymes from Erwinia carotovora. Mol. PlantMicrobe Interact. 13:430-438.

Rice, W. R. 1989. Analyzing tables of statistical tests. Evolution 43:223225.

Rogers, E. E., and Ausubel, F. M. 1997. Arabidopsis enhanced disease susceptibility mutant exhibit enhanced disease susceptibility to several bacterial pathogens and alterations in $P R-1$ gene expression. Plant Cell 9:305-316.

Rosenblueth, M., and Martínez-Romero, E. 2006. Bacterial endophytes and their interactions with hosts. Mol. Plant-Microbe Interact. 8:827-837.

Shishido, M., Loeb, B. M., and Chanway, C. P. 1995. External and internal root colonization of lodgepole pine seedlings by two growth-promoting Bacillus strains originated from different root microsites. Can. J. Microbiol. 41:707-713.

Sokal, R. R., and Rohlf, F. J. 2001. Biometry. W. H. Freeman and Company, New York.

Thompson, I. P., Bailey, J. S., Fenlon, T. R., Lilley, J. M., Lynch, P. J., McCormack, P. J., McQuilken M. P., and Purdey, K. J. 1993. Quantitative and qualitative seasonal changes in the microbial community from the phyllosphere of sugar beet (Beta vulgaris). Plant Soil 150:177-191.

Ton, J. J., Van Pelt, A., Van Loon, L. C., and Pieterse, C. M. J. 2002. Dif- ferential effectiveness of salicylate-dependent and jasmonate/ethylenedependent induced resistance in Arabidopsis. Mol. Plant-Microbe Interact. 15:27-34

Traw, B. M., Kim, J., Enright, S., Cipollini, D. F., and Bergelson, J. 2003. Negative cross-talk between the salicylate- and jasmonate-mediated pathways in the Wassilewskija ecotype of Arabidopsis thaliana. Mol. Ecol. 12:1125-1135.

Traw, B. M., Kniskern, J. M., and Bergelson, J. 2007. SAR increases fitness of Arabidopsis thaliana in the presence of natural bacterial pathogens. Evolution 61:2444:2449.

Tsuji, J., and Somerville, S. C. 1992. First report of natural infection of Arabidopsis thaliana by Xanthomonas campestris pv. campestris. Plant Dis. 76:539.

Uknes, S., Mauch-Mani, B., Moyer, M., Potter, S., Williams, S., Dincher, S., Chandler, D., Slusarenko, A., Ward, E., and Ryals, J. 1992. Acquired resistance in Arabidopsis. Plant Cell 4:645-656.

Yang, C. H., Crowley, D. E., Borneman, J., and Keen, N. T. 2001. Microbial phyllosphere populations are more complex than previously realized. Proc. Natl. Acad. Sci. U.S.A. 98:3889-3894.

Zinniel, D. K., Lambrecht, P, Harris, N. B., Feng, Z., Kuczmarski, D., Higley, P., Ishimaru, C. A., Arunakumari, A., Barletta, R. G., and Vidaver, A. K. 2002. Isolation and characterization of endophytic colonizing bacteria from agronomic crops and prairie plants. Appl. Environ. Microbiol. 68:2198-2208.

\section{AUTHOR-RECOMMENDED INTERNET RESOURCES}

University of Connecticut, R. K. Cowell's EstimateS website: purl.oclc.org/estimates

National Center for Biotechnology Information website: www.ncbi.nih.gov

EMBL-European Bioinformatics Institute ClustalW website: www.ebi.ac.uk/clustalw

Cornell University Buckler Lab for Maize Genetics and Diversity: maizegenetics.net 